\title{
Novel carbon fibers reinforced composites based on polysulfone matrix
}

\author{
Dilyus Chukov ${ }^{1, a}$, Sarvarkhodzha Nematulloev ${ }^{1}$, Andrey Stepashkin ${ }^{1}$, Aleksey Maksimkin ${ }^{1}$, Dmitriy Zherebtsov ${ }^{1}$ and Victor \\ Tcherdyntsev ${ }^{1}$
}

${ }^{1}$ NUST "MISiS", Center for composite materials, 119049 Leninskiy pr. 4, Moscow, Russia

\begin{abstract}
The aim of this study is to create composites based on the high-temperature polymer reinforced with the carbon fibers and to study interfacial interaction between carbon fibers and polymer matrix. We propose a new method to obtain polysulfone based composite materials reinforced with high-modulus carbon fibers. The influences of thermal oxidation of carbon fibers on mechanical and thermal properties of the composites were studied. It was found that the obtained composite materials have sufficiently high mechanical properties, tensile strength up to 1047 $\mathrm{MPa}$ and Young's modulus up to $70.9 \mathrm{GPa}$ were found. Considerable interest to the polymer composites is associated with their high performance and good mechanical and thermal properties, which enable a broad range of aerospace, automotive and medical applications. Additionally, the manufacturing process of such composites can easily be optimized and automatized, furthermore, it is not time-consuming process in relation with thermosetting polymer based composites.
\end{abstract}

\section{Introduction}

The development of composites combining excellent mechanical, thermal and other performance properties is a world trend in modern materials science. In past decades, a lot of attention was paid to composites based on thermoplastic polymers reinforced with continuous fibers. The growing interest in the composites caused by many attractive advantages in comparison to the widely used thermoset composites. The advantages include such properties as high fracture toughness and ductility, ease of shape forming prior to consolidation, significantly faster and lower cost manufacturing, longer shelf life of raw material [1-3]. The thermoplastic prepregs can be stored at normal environmental conditions with infinite shelf life in contrast to thermoset prepregs, whose shelf life is mainly limited. The synthesis of thermoplastic composites does not involve complex chemical reactions, therefore they can be processed with no time-consuming curing reactions [4]. Another undoubted advantage of thermoplastic composites is their ability to be reshaped and recycled by remelting the polymer matrix [5]. Therefore, to expand the scope of the composites application the development of new improved experimental techniques for the synthesis of thermoplastic composites is required.

Polysulfone (PSU) is a high performance engineering thermoplastic, which is often used in various kind of application, including tribological, aircraft and constructional applications. Possessing a number of advantages, this polymer has some drawbacks such as high processing temperature $\left(300-350{ }^{\circ} \mathrm{C}\right)$ and low adhesion to carbon fibers (CF). It is well known that the realization of fibers mechanical properties in composites mainly depends on the interfacial interaction between fillers and polymer matrix [6,7]. Using CF as effective fillers is restricted by their low adhesion to polymer due to the chemical inertness of CF surface. Various methods, such as thermal or chemical modification of fiber surface [8-10], functionalization of polymer matrix [11], plasma treatment [12-14], nanotubes application [15-17] and other [18] were applied to improve the interfacial interaction between polymers and CF. In our previous papers the effect of thermal and chemical oxidation of $\mathrm{CF}$ surface on the interfacial interaction between $\mathrm{CF}$ and ultra high molecular weight polyethylene was investigated $[19,20]$. This work is aimed to create novel composite materials based on polysulfone reinforced with carbon fibers using polymer solvent impregnation of CF. We present the results of structure and mechanical properties investigation of the obtained composites.

\section{Materials and methods}

Ultrason S2010 (Germany) PSU and twill weave fabrics 3K-1200-200 based on high-modulus carbon fibers were used as matrix and reinforces, respectively. A novel method to produce composite materials was proposed, the scheme of process is shown in Fig. 1. To ensure a uniform impregnation of carbon fibers the approach for obtaining a polymer solution was used. N-Methyl-2pyrrolidone was used as a solvent for PSU, $20 \mathrm{wt} . \%$ PSU solution was prepared using a magnetic stirrer. The PSU

${ }^{a}$ Corresponding author: dil_chukov@mail.ru 


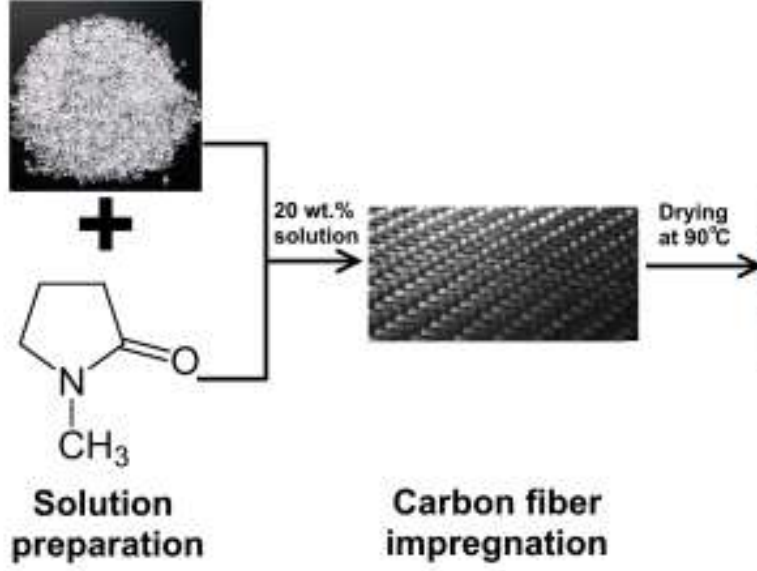

Figure 1. Preparation of polysulfone based composites

solution was used to impregnate the carbon fabrics. After impregnation the fabrics were dried at $90{ }^{\circ} \mathrm{C}$. The fiber to polymer ratio of the composites was varied as follows: 50 $\mathrm{wt} \%$ of the CF and $50 \mathrm{wt} \%$ of the PSU (denoted as 50/50), $60 \mathrm{wt} \%$ of the CF and $40 \mathrm{wt} \%$ of the PSU (60/40), 70 $\mathrm{wt} \%$ of the CF and $30 \mathrm{wt} \%$ of the PSU (70/30). The prepregs obtained after drying were compression molded at $340{ }^{\circ} \mathrm{C}$, applied pressure was of $10 \mathrm{MPa}$, and then cooled in air atmosphere. To improve the interfacial interaction between the components of the composites, surface modification of the $\mathrm{CF}$ by thermal oxidation at 300,400 and $500{ }^{\circ} \mathrm{C}$ was applied.

The structure of the composites was studied using VEGA 3 TESCAN scanning electron microscope in a backscattered electron image mode. The mechanical tests were carried out using Zwick/Roell Z020 universal test machine equipped with 1 and $20 \mathrm{kN}$ sensors and a contact strain measurement system MultiXtens. Tensile tests were carried out according to ISO 527:2009 for $110 \times 10 \times 2 \mathrm{~mm}$ samples at a speed of $10 \mathrm{~mm} / \mathrm{min}$. Flexural tests were carried out according to ISO 14125:1998 for 110x10x2 mm samples at a span length of $80 \mathrm{~mm}$ and at a speed of $10 \mathrm{~mm} / \mathrm{min}$. For all of the tests at least 5 samples were used. To study heat deflection temperature (HDT) Instron CEAST 6910 HDT/Vicat tester was used. The studies were carried out according to ISO 75 at a load of $1,8 \mathrm{MPa}$ for $80 \times 10 \times 4$ $\mathrm{mm}$ samples at a span length of $64 \mathrm{~mm}$. The HDT measurements were carried out up to $1 \mathrm{~mm}$ deflection of the composites.

\section{Results and discussion}

Reinforcing fiber content is one of the main factors that determine the mechanical properties of fiber reinforced polymer composites. Stiffness, strength and conductivity, as well as other performance properties depend mostly on the fiber content. Figure $2 \mathrm{a}$ shows the results of tensile tests of produced composites with various fiber content, as well as composites reinforced with unidirectional fibers (UD). Obviously, for the UD composites the maximum values of the tensile strength $(1220 \mathrm{MPa})$ and Young's modulus (73.9 GPa) are observed. The tensile strength and Young's modulus of composites reinforced with carbon fabrics is lower than that of UD composites

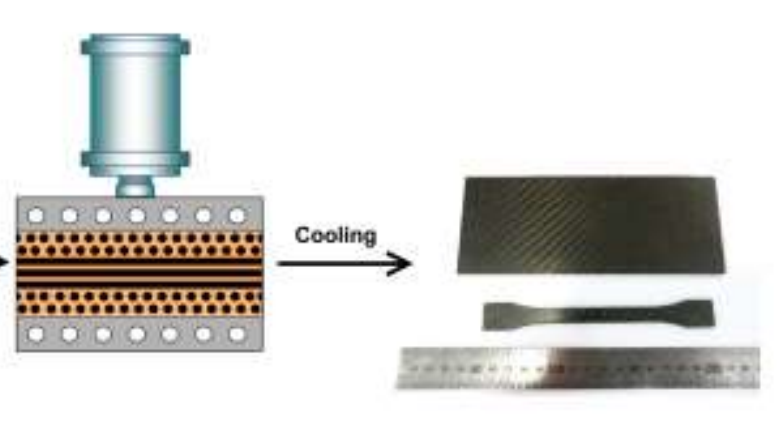

\section{Compression molding}

Final composites

and depend on CF content. The minimum value of tensile strength $(748 \mathrm{MPa})$ and the Young's modulus $(55 \mathrm{GPa})$ is observed for composites with $50 \%$ of the CF. An increase in the CF content up to $60 \%$ results in the tensile strength and the Young's modulus increase up to $880 \mathrm{MPa}$ and $57.5 \mathrm{GPa}$, respectively. Meanwhile, the composites with $70 \%$ of the CF show lower values of the strength-elastic properties (775 $\mathrm{MPa}$ and $53.7 \mathrm{GPa}$, respectively). Three point flexural tests (Fig. 2b) show that the flexural strength behavior is similar to the tensile strength. The Young's modulus thus tends to increase, and from 56.7 GPa for the 50/50 composites this value increases up to 62.7 GPa, for the $70 / 30$ composites.
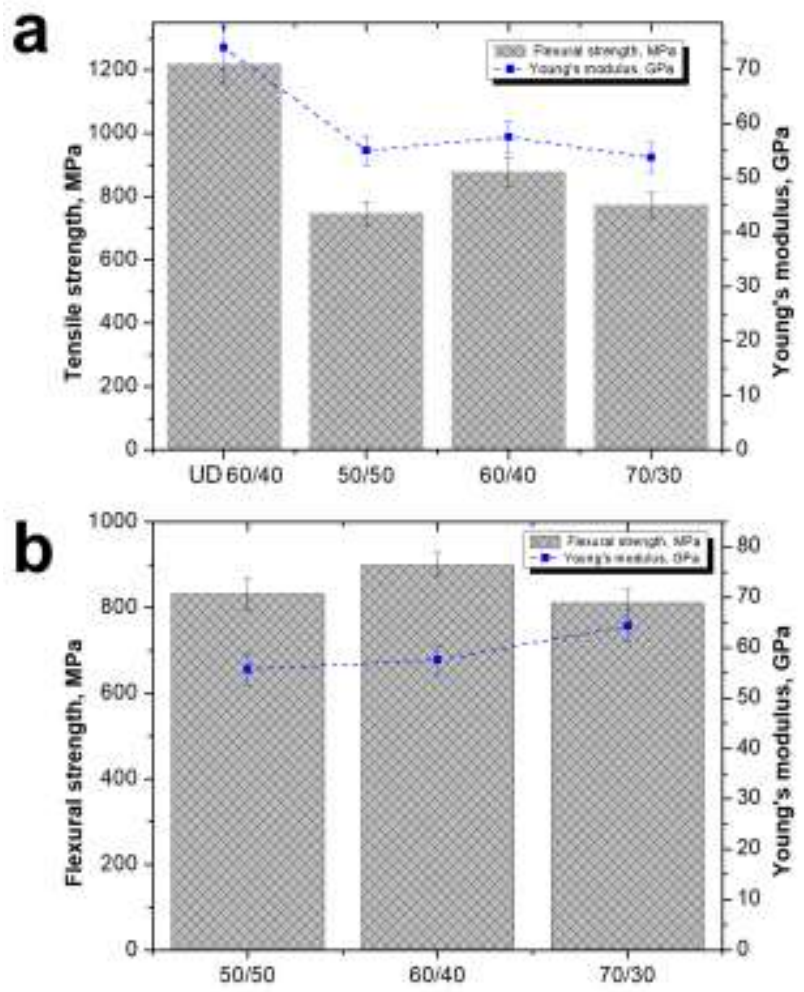

Figure 2. Mechanical properties of the composite materials: (a) tensile and (b) flexural tests

It can be concluded that at low CF content the strength of the composites is rather low because the presence of a large amount of the "weak" matrix phase. An increase in the fiber content results in a more dense 
fibers packing, while a decrease in the interlayer of polymer between the individual fibers occurs. Further increase in the $\mathrm{CF}$ content results in the decrease in the strength of the composites because in this case the matrix content is too low to binding the $\mathrm{CF}$ and to distributing the applied load to CF.

As it was mentioned earlier, the mechanical properties of composites mainly depend on the interfacial interaction between fibers and polymer matrix. To study the effect of thermal oxidation (TO) on mechanical properties the tensile and flexural tests of composites reinforced with fabrics with various TO temperatures were carried out. For these tests, the composites with an optimum fiber content of 60 wt.\%, which showed the maximum values of strength-elastic properties, were used. Table 1 summarizes results of the studies.

Table 1. Mechanical properties of the composites reinforced with fabrics after surface modification

\begin{tabular}{|c|c|c|c|c|}
\hline \multirow{2}{*}{ Designation } & \multicolumn{2}{|c|}{ Tensile tests } & \multicolumn{2}{c|}{ Flexural tests } \\
\cline { 2 - 5 } & $\boldsymbol{\sigma}_{\text {us }}, \mathbf{M P a}$ & $\mathbf{E}, \mathbf{G P a}$ & $\boldsymbol{\sigma}_{\text {us }}, \mathbf{M P a}$ & $\mathbf{E}, \mathbf{G P a}$ \\
\hline initial & $948 \pm 21$ & $56.2 \pm 3.8$ & $899 \pm 28$ & $57.6 \pm 2.4$ \\
\hline $300^{\circ} \mathrm{C}$ & $945 \pm 18$ & $56.6 \pm 3.2$ & $812 \pm 24$ & $61.5 \pm 2.3$ \\
\hline $400^{\circ} \mathrm{C}$ & $967 \pm 25$ & $61.6 \pm 3.6$ & $882 \pm 26$ & $66.2 \pm 2.1$ \\
\hline $500^{\circ} \mathrm{C}$ & $1047 \pm 16$ & $70.9 \pm 4.2$ & $1042 \pm 31$ & $73.1 \pm 2.9$ \\
\hline
\end{tabular}

$\boldsymbol{\sigma}_{u s}$ is ultimate strength; $\boldsymbol{E}$ is Young's modulus

An analysis of the results shows that the modification of the CF surface has a significant influence on the mechanical properties of the obtained composites. The maximum ultimate strength and Young's modulus values was obtained at TO temperature of $500{ }^{\circ} \mathrm{C}$. The increase in mechanical properties of the composites is associated with the increase in interfacial interaction between the polymer and the reinforcing fibers, and a higher level of adhesion for composites reinforced with modified fibers results in improve in the strength-elastic properties of the composites. It is known that modification of CF can results in an increase in the concentration of oxygen on their surface, which means an increase in the quantity of oxygen-containing functional groups, such as the hydroxyl $(-\mathrm{OH})$, carbonyl $(-\mathrm{C}=\mathrm{O})$ and carboxyl $(-\mathrm{COOH})$ groups $[21,22]$. These functional groups contribute to the formation of the chemical bonds between $\mathrm{CF}$ and polymer, which results in the formation of strong interface in the composites.

Scanning electron microscopy showed (Fig. 3a) that the developed method for obtaining $\mathrm{CF}$ reinforced composites allows to well impregnation of the carbon fabrics with the polymer. The polymer matrix penetrates not only between individual threads of the fabric, but impregnates the threads, penetrating between the filaments of the carbon fibers.
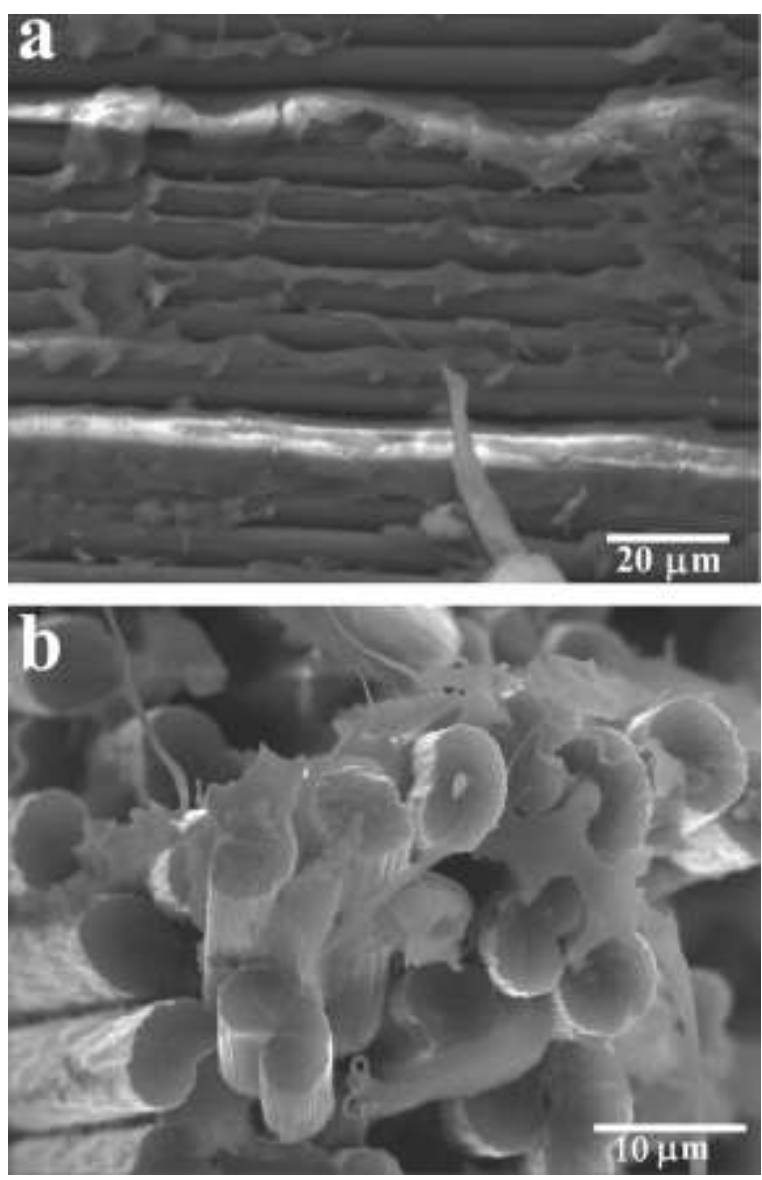

Figure 3. Structure of the composites reinforced with (a) initial and (b) oxidized at $500{ }^{\circ} \mathrm{C}$ carbon fibers

However, for a composites reinforced with the initial $\mathrm{CF}$ is typical a rather low level of interfacial interaction. The surface modification of the $\mathrm{CF}$ can improve interfacial interaction in the composites, and even after fracture, individual filaments can be coated with a thin continuous film of the polymer (Fig. 3b). The observed improvement in adhesion provides the high mechanical properties of composites reinforced with modified CF.

To evaluate the heat resistance a heat deflection temperature (HDT) of the produced composites were studied. The results of the studies are shown in Figure 4.

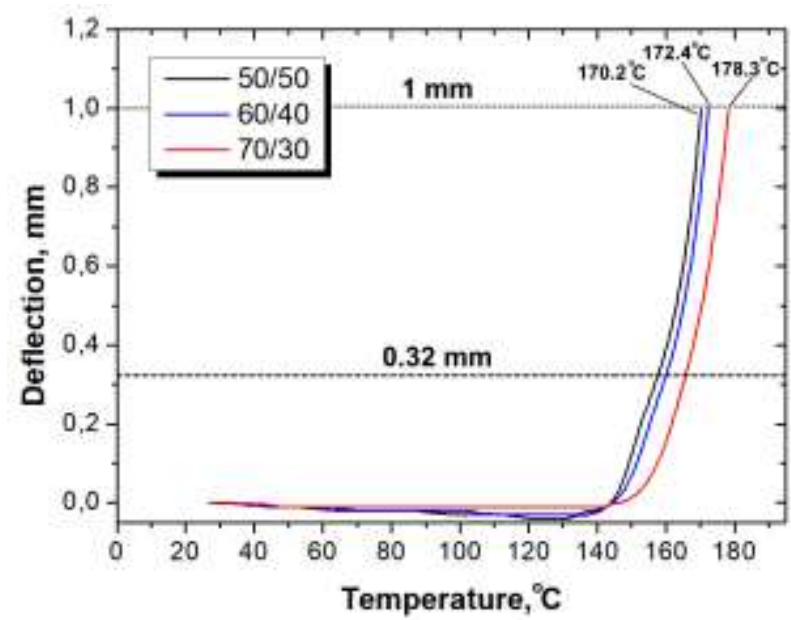

Figure 4. Heat deflection temperature of the composites with various fibers content 
It was found that an increase in the fiber content is accompanied by an increase in the heat deflection temperature of the composites. The minimum HDT values (at deflection of $0.32 \mathrm{~mm}$ ) are typical for a $50 / 50$ composites $\left(156.7^{\circ} \mathrm{C}\right)$, and maximum HDT values were observed for a $70 / 30$ composites $\left(166.3^{\circ} \mathrm{C}\right)$. Deflection of $1 \mathrm{~mm}$ is reaches at temperature range of $170-178{ }^{\circ} \mathrm{C}$ depending on CF content. Consequently, the dependencies obtained for composites with different polymer to fiber ratios can be interpreted as an increase in the heat resistance of the composites with increase in $\mathrm{CF}$ content. It is known that the loss of stability, including at the HDT tests, for amorphous polymers approximately coincides with glass transition temperature Tg values of the polymer. Consequently, loss of stability in the temperature range of $170-180{ }^{\circ} \mathrm{C}$ indicates that the heat resistance of the produced composites is mainly determine by the transition of the polymer matrix from the glassy state to the highly viscous (rubbery) one.

\section{Conclusions}

A novel method to obtain composites based on polysulfone reinforced with carbon fibers was proposed. The results of the structure, mechanical and thermal properties investigation of the produced composites were presented. The influence of the CF content and surface modification of the $\mathrm{CF}$ on strength-elastic properties of the composites was analyzed. It was found that the obtained composite materials have a sufficiently high level of mechanical properties (tensile strength up to $1047 \mathrm{MPa}$ and Young's modulus up to $70.9 \mathrm{GPa}$ ), which is comparable to such well-known and widely used thermoset materials as the carbon fiber reinforced epoxy matrix composites. Obtained composites can be competitive in the construction materials market due to their faster and lower cost manufacturing, excellent thermal and mechanical properties.

\section{Acknowledgments}

The reported study was funded by Russian Science Foundation grant No. 18-19-00744.

\section{References}

1. J. Wang, K.-X. Li, H.-W. He, J.-L. Wang, and G.-H. Sun, Colloids Surf. Physicochem. Eng. Asp. 377, 330 (2011).
2. T. Zhao, G. Palardy, I. F. Villegas, C. Rans, M. Martinez, and R. Benedictus, Compos. Part B Eng. 112, 224 (2017).

3. H. Shi, I. F. Villegas, and H. E. N. Bersee, Compos. Part Appl. Sci. Manuf. 55, 1 (2013).

4. V. Benoit, L. Cédric, and C. Alexis, Mater. Des. 63, 56 (2014).

5. L. Ye, Z.-R. Chen, M. Lu, and M. Hou, Compos. Part Appl. Sci. Manuf. 36, 915 (2005).

6. M. Sharma, S. Gao, E. Mäder, H. Sharma, L. Y. Wei, and J. Bijwe, Compos. Sci. Technol. 102, 35 (2014).

7. J. Moosburger-Will, J. Jäger, J. Strauch, M. Bauer, S. Strobl, F. F. Linscheid, and S. Horn, Compos. Interfaces 24, 691 (2017).

8. F. Severini, L. Formaro, M. Pegoraro, and L. Posca, Carbon 40, 735 (2002).

9. C. M. Vaz, R. L. Reis, and A. M. Cunha, Biomaterials 23, 629 (2002).

10. A. A. Stepashkin, D. I. Chukov, V. V. Cherdyntsev, and S. D. Kaloshkin, Inorg. Mater. Appl. Res. 5, 22 (2014).

11. H. J. Salavagione and G. Martínez, Macromolecules 44, 2685 (2011).

12. L. L. G. Silva, A. L. Santos, P. A. P. Nascente, and K.

G. Kostov, J. Phys. Conf. Ser. 511, 012082 (2014).

13. Y. Zhao, C. Zhang, X. Shao, Y. Wang, and Y. Qiu, J. Adhes. Sci. Technol. 25, 2897 (2011).

14. K. Y. Rhee, S. J. Park, D. Hui, and Y. Qiu, Compos. Part B Eng. 43, 2395 (2012).

15. A. R. Alian, S. I. Kundalwal, and S. A. Meguid, Compos. Struct. 131, 545 (2015).

16. S. I. Kundalwal and S. A. Meguid, Eur. J. Mech. ASolids 64, 69 (2017).

17. S. I. Kundalwal and M. C. Ray, J. Mech. Mater. Struct. 9, 1 (2014).

18. S. Tiwari and J. Bijwe, Procedia Technol. 14, 505 (2014).

19. D. I. Chukov, A. A. Stepashkin, V. V. Tcherdyntsev, S. D. Kaloshkin, and V. D. Danilov, Inorg. Mater. Appl. Res. 5, 386 (2014).

20. A. A. Stepashkin, D. I. Chukov, M. V. Gorshenkov, V. V. Tcherdyntsev, and S. D. Kaloshkin, J. Alloys Compd. 586, S168 (2014).

21. J. P. Boudou, J. I. Paredes, A. Cuesta, A. MartínezAlonso, and J. M. D. Tascón, Carbon 41, 41 (2003).

22. R. Fu, L. Liu, W. Huang, and P. Sun, J. Appl. Polym. Sci. 87, 2253 (2003). 